\section{Ali DiRiCAN ${ }^{1}$ \\ İsa TELCi2}

\title{
Tokat Florasında Doğal Yayılış Gösteren Rezene Popülasyonlarının Morfolojik ve Kalite Özeliklerinin Belirlenmesi
}

\author{
Determination of Morphological and Quality Characters in \\ Native Fennel Populations from Flora of Tokat
}

Gaziosmanpaşa Universitesi, Fen Bilim 60240, Tokat / Türkiye

2 Süleyman Demirel Üniversitesi, Ziraat Fakültesi, Tarla Bitkileri Bölümü, 32260, Isparta / Türkiye

sorumlu yazar: isa.telci@sdu.edu.tr

Anahtar Sözcükler:

Rezene, Foeniculum vulgare, uçucu yağ, estragol

Key Words:

Fennel, Foeniculum vulgare, essential oil, estragole

\section{GíRiş}

Umbelliferae (Apiaceae) familyasına ait olan Foeniculum vulgare Mill. Türkçede rezene, raziyane, arapsaçı isimleriyle bilinmektedir (Baytop, 1994). Rezene uzun yıllardan beri bilinen ve kültürü yapılan bir bitkidir. Doğal ve kültür formları tek bir türe aittir. Diğer bir ifadeyle Foeniculum cinsi Dünyada tek bir tür (vulgare) içermektedir. Ancak bu türe ait subsp. vulgare (sinonim: capillaceum) ve subsp. piperitum olmak üzere iki alt tür, subsp. vulgare'ye ait üç varyete (var. vulgare, var dulce, var azoricum ) bulunmaktadır (Piccaglia and Marotti, 2001). Davis (1972), Türkiye florasında bulunan Foeniculum vulgare'yi tür bazında incelese de; sonraki yıllarda yayınlanan kayıtlarda, 
doğal yayılış gösteren rezene popülasyonlarında alt türlerin bulunduğu ve toplanarak kullanıldığı anlaşılmaktadır (Özcan et al., 2006).

Rezene Türkiye'nin dışarıya ihraç ettiği tıbbi bitkilerdendir (Bayram ve ark., 2010). Türkiye'de Burdur, Denizli, Uşak ve çevresinde tarımının da yapıldığı bilinmektedir. Rezene kültür formlarının olgunlaşmış meyvelerinin içerdiği uçucu yağ nedeniyle kullanılmaktadır. Uçucu yağ kompozisyonu üzerinde yoğun çalışmalar bulunmaktadır. Yapılan çalışmalarda rezene meyvelerinde uçucu yağ ana bileşenlerinin çoğunlukla fenil propenoit gurubundan trans-anethol veya estragol (metil kavikol) olduğu belirlenmiştir (Guillen and Manzanos,1994; Bernath et al., 1996). trans-Anetol daha çok kültür formlarında fazla bulunan bileşik iken, estragol yabani formlarda daha yaygın bulunmaktadır (Telci et al., 2009; Napoli et al., 2010). Diğer önemli bileşikler fenkon ve limonendir. Muckensturm et al. (1997) rezenenin doğal ve kültür formlarında trans-anetol (kültür formlarında) ve estragol bakımından zengin kemotiplerin bulunduğu ve meyve uçucu yağında en yüksek trans-anethol ve estragol oranlarının sırasıyla $\% 65$ ve \% 60 olduğunu belirtmişlerdir. Sicilya'da doğal yayılış gösteren rezene popülasyonlarında; ana bileşenin estragol olduğu ve \% 34- 78 arasında değiştiği, trans-anetol oranının ise \% $0.1-36$ aralıklarında bulunduğu bildirilmiştir (Napoli et al., 2010).

Rezene kültür formlarında yoğun çalışmalar bulunmasına rağmen doğal popülasyonların üzerindeki çalışmalar sınırlıdır. Özcan and Chalchat (2006) Mersin'den iki farklı yılda toplanan örneklerde, ana bileşenin estragol olduğu ve bunu fenkon ve limonenin takip ettiğini bildirmişlerdir. Türkiye'de rezene yetiştiriciliği üzerindeki çalışmalara rağmen, doğal popülasyonların varyasyonu üzerinde yapılan çalıșmalar sınırlıdır. Ayrıca rezenenin doğal yayılış gösterdiği orta Karadeniz popülasyonları üzerinde morfolojik ve teknolojik çalışma bulunmamaktadır. Bu nedenle mevcut çalışmada; Orta Karadeniz bölgesinde yer alan Tokat florasında doğal yayılış gösteren rezenelerin bitkisel ve kalite özellikleri ile bu özellikler arası ilişkiler incelenmiştir. Ayrıca çalışmada bu popülasyonların tarımsal önemi ve ekonomik kullanılabilirliğinin ortaya çıkarılması amaçlanmıştır.

\section{MATERYAL ve YÖNTEM}

\section{Araştırma Alanı ve Bitki Materyali}

Bitki materyalinin toplandığı Tokat florası Orta Karadeniz bölgesinde yer almaktadır. Bölge ılıman Karadeniz ile yazları kurak ve kışları soğuk karasal iklim arasında geçiş özelliği göstermektedir. Araştırmaya konu olan yabani rezene (Foeniculum vulgare Mill.) popülasyonları Tokat florasının yer aldığı A6 karesinde, 2011 yılı Ağustos-Eylül aylarında toplanmıştır. Bu geziler iki farklı dönemde yapılmıştır. Gezilerin birincisi çiçeklenme döneminde, bitkinin yoğun bulunduğu alanları belirlemek ve herbaryum örnekleri alınmak için yapılmıştır. Geziler sonucu bitkilerin toplanacağı yerler belirlenmiştir. Bitki toplanan yerlere ait (Durak) bilgiler Çizelge 1'de özetlenmiştir.

Çizelge 1. Bitki örneklerinin alındığı duraklara ait özellikleri

Table 1. Proportion of areas where plant samples were taken

\begin{tabular}{|l|l|}
\hline Duraklar & Durak özellikleri \\
\hline Durak-I & $\begin{array}{l}\text { Kuzey } 4020166-4021240 \text { enlemleri ile Doğu } 3631711-3632876 \text { boylamları aralıklarında, taban arazı ve bitkilerin suya } \\
\text { kolayca ulaşabilecekleri daha çok sulama kanalı etrafında ve tarla bahçe kenarlarından oluşmuştur. Bitkiler ağaç } \\
\text { gölgelerinde de bitkilerin bulunduğu gözlenmiştir. Ortalama rakım } 636 \mathrm{~cm} \text { dir. }\end{array}$ \\
\hline Durak-II & $\begin{array}{l}\text { Kuzey } 4017354-4021437 \text { enlemleri ile Doğu } 3632149-3633254 \text { boylamları aralıklarında yer alır. Ortalama rakım } 689 \\
\text { m'dir. Yükseltinin artmasıyla ters orantılı olarak bitki yoğunluğu ve ihtiyaç duyulan suya ulaşma imkanı Durak-I' göre } \\
\text { nispeten azalır. Tarım alanlarından uzak alandan oluşmuştur. }\end{array}$ \\
\hline Durak-III & $\begin{array}{l}\text { Kuzey } 4015240-4017494 \text { enlemleri ile Doğu } 3632774-3633204 \text { boylamlarında yer alan, ortalama rakımın } 690 \mathrm{~cm} \\
\text { olduğu alanlardır. Durak - II'ye benzer özelikte olmakla birlikte örnek alınan noktalar daha eğimli ve kıraç alanlardır. }\end{array}$ \\
\hline Durak-IV & $\begin{array}{l}\text { Kuzey } 4014395-4014769 \text { enlemi ile Doğu } 3632774-3633204 \text { Doğu boylamında ortalama rakımın } 786 \text { olduğu alanlardır. } \\
\text { Bitkilerin doğal yağıslardan başka su imkanına sahip değildir. Örneklerin alındığı alanlar taşlık alanlardır. }\end{array}$ \\
\hline
\end{tabular}


Çalışmada, ikinci toplama gezileri ise meyve olgunlaştığı dönemde önceden belirlenen alanlara olgun meyveleri toplamak amacıyla düzenlenmiştir. Bitkilerde meyveler, bitki boyu $(\mathrm{cm})$, dal, şemsiye ve şemsiyecik (ana şemsiyede) sayıları alındıktan sonra toplanmıştır. Toplanan meyveler laboratuvar koşullarında etüvde $35{ }^{\circ} \mathrm{C}$ 'de sabit ağırlığa (nem \% $9 \pm 1$ ) ulaşıncaya kadar kurutulmuştur. Yukarıda belirlenen özelliklere ilaveten toplanan meyvelerde meyve boyutları, 1000 meyve ağırlığı (g) gibi morfolojik özelliklerde incelenmiştir. Kalite özeliklerinden renk değerleri Minolta (CR-400) Marka renk ölçerle belirlendikten sonra aşağıda açıklanan diğer kalite özelikleri incelenmiştir.

\section{Uçucu Yağ Analizi}

Uçucu yağ oranı (\%), toplanan bitkilerde $10 \mathrm{~g}$ 'lık olgunlaşmış meyve örnekleri $100 \mathrm{ml}$ saf su içerisinde clevenger aparatıyla 3 saat distilasyona tabi tutulmuştur. Distilasyon sonucu toplama bölümünde biriken yağın hacmi $\mathrm{ml} / 100 \mathrm{~g}(\% \quad)$ olarak hesaplanmıştır (Telci et al., 2009).

\section{Ana Bileşen Analizleri}

Uçucu yağ bileşenleri Gaz Kromatografisi Kütle Spektroskopisiyle (GC-MS) belirlenmiştir. Bu amaçla Gaziosmanpaşa Üniversitesi Fen-Edebiyat Fakültesi Kimya Bölümünde Autosampler sistemi bulunan Perkin Elmer marka 500 GC model cihaz kullanılmıştır. GC/MS ayırımı için, $70 \mathrm{eV}$ iyonization enerjili, elektron iyonlaşma sistemi kullanılmıştır. Taşıyıcı gaz olarak kullanılan helyumun akış oranı $1.3 \mathrm{~mL} / \mathrm{dk}$. Kullanılan kolon BPX5 ( $30 \mathrm{~m} \times 0.25 \mathrm{~mm} \times 0.25 \mu \mathrm{m}$ film kalınlığı) olup, başlangıç sıcaklığı $50{ }^{\circ} \mathrm{C}$ olup $120{ }^{\circ} \mathrm{C}$ kadar 3 ${ }^{\circ} \mathrm{C} /$ min. $120{ }^{\circ} \mathrm{C}$ 'den $220{ }^{\circ} \mathrm{C} \quad 5{ }^{\circ} \mathrm{C} / \mathrm{min}$ olarak programlanmıştır. Enjektör ve MS transfer sıcaklıkları sırasıyla $230^{\circ} \mathrm{C}$ ve $250^{\circ} \mathrm{C}$ olacak şekilde ayarlanmıştır. Elde edilen uçucu yağlar Gaz Kromatografisinde olduğu gibi asetonla 1:10 oranında seyreltildikten sonra örnekten $1.0 \mathrm{~L}$ gaz kromatografisine enjekte edildi. Split oranı 5:1 olarak ayarlanmıştır. Analizler sonucu en fazla bulunan bileşiklerin standartlarının karşılaştırıması ile tanımlanmıştır. Ayrıca bu bileşikler WILLEY ve NIST kütüphaneleriyle teyit edilmiştir. Pik alanı \% olarak hesaplanmıştır.

\section{Elde Edilen Verilerin Değerlendirilmesi}

Incelenen her bir özelliğin (uçucu yağda ana bileşenleri dâhil), maksimum- minimum değerleri, ortalamaları, standart sapması ile özellikler arasındaki korelasyon değerleri hesaplanmıştır. Tüm bu işlemlerde SPSS İstatistik Programları (ver: 20.0) kullanılmıştır.

\section{ARAŞTIRMA BULGULARI ve TARTIŞMA}

\section{Bitkisel Özelikler}

Çalışmada, Durak-I'den 19, Durak-II ve Durak-III'ten 7 ve Durak-IV'ten 4 örnek alınarak bu örneklere ait değişim aralıkları, ortalamaları ve standart sapmaları ile tüm durakları içeren genel değerler Çizelge 2'de verilmiştir. Bitkilerde bitki boyu $100-235 \mathrm{~cm}$ arasında değişmiştir. Bu değişimde en düşük değer $100 \mathrm{~cm}$ ile Durak-IV'ten en yüksek değer ise $235 \mathrm{~cm}$ ile DurakI'den alınmıştır. Ortalama bitki boyları ise duraklara göre sırasılyla $187.8 \mathrm{~cm}, 177.8 \mathrm{~cm}, 189.5 \mathrm{~cm}$ ve 169.2 $\mathrm{cm}$ olarak belirlenmiştir (Çizelge 2). Ortalama ve değişim aralıkları bakımından Durak-IV değerleri diğer duraklardan daha düşük olmuştur. Bu durum örnek sayısıyla rakımı yüksek, eğimli ve kıraç bir özeliğe sahip olan Durak-IV'ün özeliğinden kaynaklandığı düşünülmektedir (Çizelge 1). Çalışmada toplanan rezene bitkilerinin bitki boyları kültürü yapılan rezene genotiplerinden oldukça yüksek olduğu görülmektedir. Türkiye'de kültürü yapılan bitkilerde en yüksek değerler $1 \mathrm{~m}(88-94 \mathrm{~cm})$ civarındayken (Özkan, 1999), Ehsanipour et el., (2012) azot dozlarına göre bitki boyunun 177-220 cm arasında değiştiğini bildirmiştir. Davis (1972) doğal yayılış gösteren popülasyonlarda bitki boyunun $100-180 \mathrm{~cm}$, Tanker ve ark., (2004) 100-150 cm, Ceylan (1987) ise 200 cm'ye kadar çıktığını belirmiştir. Çalışmada bitki boyuna ait değerleri Türkiye'de kültürü yapılan genotiplerden yüksek olduğu görülmektedir.

Çalışmada dal sayısı 6.5-14.5, şemsiye sayısı 10.534.0 ve ana şemsiyede şemsiyecik sayısı $15.0-30.5$ adet arasında değişmiş; ortalama değerler sırasıyla 9.6, 21.2 ve 22.7 olmuştur (Çizelge 2). Duraklara göre ortalama değerlerde dal ve şemsiyecik sayısı Durak-III'te şemsiye sayısı ise Durak-I'de yüksek bulunmuştur. Dal, şemsiye ve ana şemsiyede şemsiyecik sayısı bitkinin genetik yapısı yanında yetişme koşullarına göre değişim göstermektedir. Tunçtürk ve ark. (2011) dal ve şemsiye sayılarının sırasıyla 5-7 ile 7-12 arasında; Mahfouz and Sharaf-Eldin (2007) ise dal sayısının 6-8 adet arasında değiştiğini belirtmiş̧ir. Ehsanipour et al. (2012) rezenede şemsiye sayısının 40-75 adet arasında değiştiğini belirtirken El-Awadi and Hassan (2010) ise şemsiye sayısını 10-11 olarak belirtmiştir. Belirlediğimiz şemsiye sayısı Ehsanipour et al. (2012) değerlerinden düşük, Tunçtürk ve ark. (2011) ile Mahfouz and Sharaf-Eldin (2007)'un değerlerinden ise yüksek bulunmuştur. 


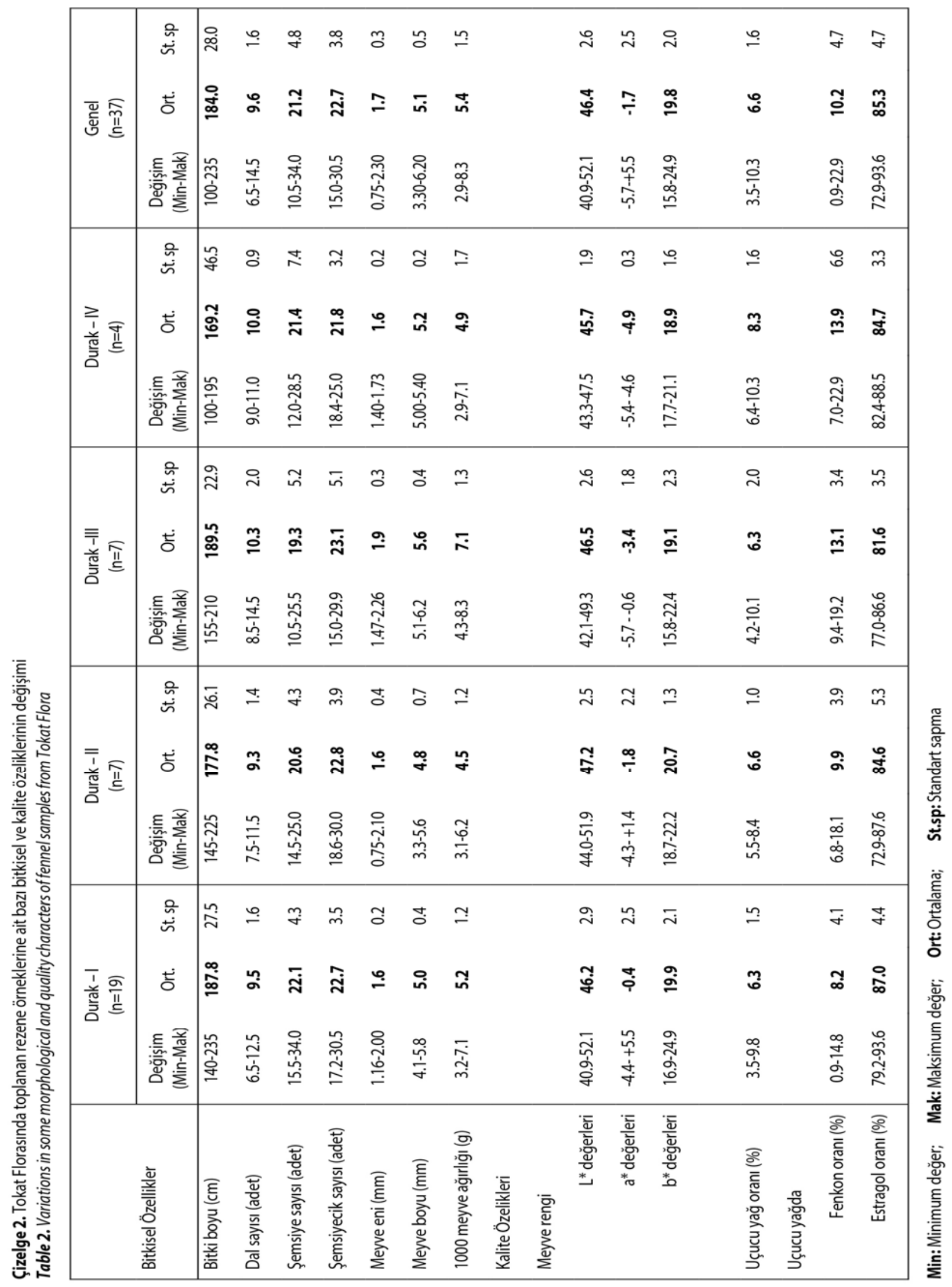


Çalışmada meyve eni $0.75-2.30 \mathrm{~mm}$, meyve boyu $3.30-6.20 \mathrm{~mm}$ ve 1000 meyve ağırlığı ise $2.9-8.3 \mathrm{~g}$ aralıklarında değişmiştir. Ortalama değerlerde ise meyve eni $1.7 \mathrm{~mm}$ olurken, meyve boyu ise $5.1 \mathrm{~mm}$ olarak hesaplanmıştır. 1000 meyve ağırlığına ait ortalama değer ise $5.4 \mathrm{~g}$ olarak belirlenmiştir. Çalışmada Durak-III'te meyve boyutları (en-boy) ile 1000 meyve ağırlığı ortalama değerleri diğer duraklardan yüksek olmuştur. Rezene gibi Apiaceae familyası bitkilerde meyve yapısı şizokarp olup iki merikarpten oluşmaktadır. Rezenede olgun şizokarplarda merikarplar ayrılmadığından dolayı meyve boyutları ile 1000 meyve ağırlığı zarar görmemiş örneklerde belirlenmiştir. Çalışmada belirlenen 1000 meyve ağırlığı değerlerinin (2.9- $8.3 \mathrm{~g}$ ) literatür değerlerinden daha değişken olduğu görülmüştür. Rezenede 1000 meyve ağırlığına ait literatür değerleri incelendiğinde 3.5 gramdan 8.2 grama kadar çıkabilmektedir (Tunçtürk ve ark., 2011; Ehsanipour et al., 2012). Ancak 1000 meyve ağırlığı kültürü yapılan popülasyonlarda daha tekdüze ve değişim azken, mevcut çalışmada olduğu gibi doğal formlarda daha fazladır. Yabani formların 1000 meyve ağırlığındaki değişimin, fazlalığı, bitkinin dallanma durumu, yan şemsiye sayılarının fazlalığı ve yan şemsiyelerdeki meyvelerin daha küçük olmasından kaynaklandığı düşünülmektedir. Bitkide meyve ağırlığı bitkinin genetik yapısı ile ekolojik faktörler yanında, meyvenin aynı bitki üzerindeki konumuna göre de farklılık göstermektedir. Telci et al. (2009) ana şemsiyede 1000 meyve ağırlığının 4.5-8.0 g, yan dallardaki meyve ağırlığının ise 2.0-8.0 $\mathrm{g}$ arasında değiştiğini belirtmiştir.

\section{Kalite Özelikleri}

Çalışmada toplanan örneklerde kalite özelikleri olarak meyve rengi, uçucu yağ oranı ve uçucu yağda en fazla bulunan ana bileşenlerden fenkon ve estragol oranları incelenmiştir. Tüm gıdalarda olduğu gibi baharatlarda renk ve görünüm ürün kalitesinde önemli fikir vermektedir. Ürünlerde renk ölçüm değerleri olan $L(100=$ beyaz, $0=$ siyah) değeri dikey eksende parlaklıktan koyuluğa gidişi belirlerken, $+a$ kırmızılığa - a yeşilliğe, $+b$ sarılığa $-b$ ise maviliğe gidişi göstermektedir. Çalışmada meyvelerde $L$ değerleri 40.952.1 , a değerleri -5.7 ile +5.5 arasında $b$ değerleri ise 15.8-24.9 arasında değişim göstermiștir. Örneklerde L ve $b$ değerlerinde keskin değişmeler görülmezken $a$ değerlerinde daha fazla değişim gözlenmiştir. Ürünlerde + a değerleri kırmızılığı, - a değerleri yeşilliği ifade etiğinden, meyvelerde olgunlaşmadan kaynaklanan renk değişimleri a değerleriyle daha bariz ortaya çıkmıştır. Rezene bitkisi fazla dallandığından meyvelerdeki olgunlaşma farklılı̆ı a değerlerindeki değişimin farklı olmasına neden olmuştur. Tüm duraklardaki ki örneklerde ortalama değerler - a değerlerine sahip olup, olgun meyveler hafif yeşile çalmaktadır. Literatürde rezenede renk ölçümüne ait bir kayıt bulunmamasına rağmen, rezenede rengin Ceylan (1987) kahverengi- yeşil, Baydar (2013) yeşilimsi gri, Baytop (1999) esmerimsi yeşil veya yeşilimsi sarı renkte olduğunu belirtmişlerdir.

Rezenede kullanıma neden olan madde meyvelerdeki uçucu yağ oranı olup, çalışmada uçucu yağ oranları \% 3.5-10.3 arasında değişmiş ve ortalama değer \% 6.6 olarak bulunmuştur. Lokasyonlara göre ortalama değerler ise Durak-I ve Durak-III'te \% 6.3; Durak II ve Durak IV'te sırasıyla \% 6.6 ve 8.3 olarak belirlenmiştir. Uçucu yağ oranı bakımından maksimum değer (\%10.3) ile en yüksek ortalama değer (\%8.3) Durak-IV'ten alınan örneklerden elde edilmiştir. Rezene aromatik bitkiler içerisinde yüksek oranda uçucu yağ içeren bitkiler arasındadır. Literatürlerde rezenede uçucu yağ oranlarını Ceylan (1987) \% 3.5-6, Baytop (1999) \% 3-7, Tanker ve ark. (2004) ise \% 3-6 arasında olduğunu belirtmişlerdir.

Benzer çalışmalarda rezenede uçucu yağ oranlarının Şanlı ve ark. (2008) \% 2.32- 4.95 arasında değiştiğini, Baydar (2013) ise tatlı rezenede \% 2-4, acı rezenede ise \% 3-6 arasında olduğunu, Akgün (1990) tatlı rezenenin \% 2-3, acı rezenenin ise \% 3-7 uçucu yağ içerdiğini belirtmişlerdir. Telci et al (2009) ana şemsiyelerde uçucu yağ oranlarının gelişme dönemlerine göre \% 3.0-6.0 arasında değiştiğini belirtmiştir. Örneklerin çoğunda (\% 80'den fazla) uçucu yağ oranları literatürde belirtilen sınırlar içerisinde yer almıştır. Ancak çalışmada literatürde belirtilen değerlerin üzerinde uçucu yağ içeren örneklerin de bulunduğu belirlenmiştir. Bazı araştırıcıların ifade ettiği gibi (Baydar, 2013) acı rezenelerde uçucu yağ oranının tatlı rezenelerden daha yüksek olduğu görülmektedir. Acı rezeneler daha çok doğal örnekler olup vulgare varyetesine sahiptirler. Çalışmada örneklerde uçucu yağ oranının yüksek olması literatürdeki bu bilgilerle uyumluluk göstermektedir.

Çalışmada uçucu yağ içerisindeki ana bileşenlerin estragol ve fenkon olduğu belirlenmiş ve bunların değişimi incelenmiştir. Estragol, tüm örneklerde en fazla bulunan bileşik olup, \% 72.9-93.6 (ortalama $\%$ 85.3) arasında değişmiştir. En yüksek estragol oranı \% 87.0 ile Durak-I'den elde edilmiş bunu Durak IV ve Durak II takip etmiştir. Durak-III'te ise oranlar diğer duraklardan biraz daha düşük olmuştur. Çalışmada diğer önemli bileşik fenkon tüm örneklerdeki genel değişimi \% 0.9-22.9 arasında, ortalama değer ise 
\% 10.2 olarak bulunmuştur. Estragolun aksine fenkon oranında en düşük ortalama değer \% 8.2 ile DurakI'den elde edilmiştir. En yüksek fenkon oranları ise estragol oranlarının düşük olduğu Durak -III ile DurakIV'ten alınmıştır. Rezene uçucu yağ kompozisyonu bakımından azda olsa farklı kemotipler bulunmasına rağmen, rezene meyvelerinde trans-anetol veya onun izomeri olan estragol (metik kavikol) en fazla bulunan bileşiklerdir (Muckensturm et al 1997). Bu çalışmada toplanan tüm örneklerde ana bileşenin estragol olduğu belirlenmiştir. Kültür formlarından olan var dulce, trans-anetol bakımından zengin olurken, acı rezene olarak bilinen ve doğal yayılış gösteren vulgare estragol bakımından zengin kemotipler içermektedir (Napoli et al 2010). Bu çalışmada elde edilen veriler literatürde en fazla oranda estragol içeren örnekler kadar olduğu belirlenmiştir (Napoli et al 2010). Çalışmada rezene yağına acılık veren fenkon oranlarının değişim sınırları literatür değerleri arasında yer almaktadır (Muckensturm et al 1997; Napoli et al 2010).

\section{Özellikler Arası İlişkiler}

Incelenen morfolojik ve kalite özeliklerine ilişkin korelasyon katsayıları hesaplanarak Çizelge 3'te verilmiştir. Ayrıca özelliklerle rakım arasındaki korelasyon katsayıları da hesaplanmıştır. Bu sonuçlara göre bitki boyu ile ana şemsiye sayısı $\left(r=0,038^{*}\right)$ ve estragol $\left(r=0,60^{* *}\right)$ oranı arasında olumlu ve önemli ilişkinin olduğu belirlenmiştir. Ancak bitki boyunun yüksekliğe çıkıldıkça anlamlı oranda azaldığı, bitki boyu ile rakım arasında önemli düzeyde olumsuz ilişkinin $\left(-0,34^{*}\right)$ olduğu gözlenmiştir. Yüksek rakımlara doğru ışık şiddetinden kaynaklanan nedenlerden dolayı bitki boyunun kısaldığı bilinmektedir (Sencar ve Gökmen 1996). Çalışmada bitki boyuna bağlı olarak şemsiye sayılarının da artığı ve bitki boyu ile şemsiye sayıları arasında olumlu bir ilişkinin olduğu belirlenmiştir. Çalışmada şemsiye sayısı ile şemsiyecik sayısı arasında olumlu ilişkinin $\left(r=0,34^{*}\right)$ yanında, meyve boyutları ile meyve ağırlığı (1000 meyve ağırlığı) özellikleri (en boy sırasıyla $r=0,65^{* *}$ ve $r=0,42^{*}$ ) arasında önemli ve olumlu ilişkilerin olduğu belirlenmiştir. Doğal olarak meyve büyüklüğü (eni ve boyu) artıkça 1000 meyve ağırlığının da artacağı beklenmektedir.

Meyve boyu ile fenkon oranı arasında olumlu ve önemli $\left(r=0,33^{*}\right)$ ilişki yanında, uçucu yağ ile ana bileşen estragol oranı $\left(r=--0,34^{*}\right)$ arasında olumsuz önemli ilişki gözlenmiştir. Diğer bir ifadeyle uçucu yağ oranı yüksek örneklerde estragol oranı düşük bulunmuştur. Çalışmada rakımla fenchon arasında önemli ve olumlu $\left(r=0,53^{* *}\right)$ korelasyon gözlenirken, rakımla estragol arasında $\left(r=-0,37^{*}\right)$ önemli fakat negatif korelasyon gözlenmiştir.

Çizelge 3. Incelenen özellikler arası korelasyon katsayıları

Table 3. Correlation coefficients among examined characters

\begin{tabular}{|c|c|c|c|c|c|c|c|c|c|c|}
\hline Özelikler & 2 & 3 & 4 & 5 & 6 & 7 & 8 & 9 & 10 & 11 \\
\hline 1. Bitki Boyu $(\mathrm{cm})$ & 0.26 & $0.38^{*}$ & 0.21 & -0.03 & 0.13 & .09 & -0.02 & -0.19 & $0.60^{* *}$ & $-0.34^{*}$ \\
\hline 2. Dal sayısı (adet/bitki) & - & .17 & -0.03 & 0.06 & 0.31 & .12 & 0.05 & 0.19 & 0.05 & 0.21 \\
\hline 3. Şemsiye Sayısı (adet/bitki) & & - & $0.34^{*}$ & -0.17 & -0.26 & -.030 & -0.18 & -0.09 & $0.39^{*}$ & -0.07 \\
\hline 4. Şemsiyecik sayısı (adet/şemsiye) & & & - & -0.09 & -0.26 & -.089 & -0.14 & -0.09 & 0.13 & 0.06 \\
\hline 5. Meyve eni $(\mathrm{mm})$ & & & & - & $0.69^{* *}$ & $0.65^{* *}$ & -0.02 & 0.28 & -0.05 & 0.15 \\
\hline 6. Meyve boyu (mm) & & & & & - & $0.42^{*}$ & 0.21 & $0.33^{*}$ & -0.11 & 0.19 \\
\hline 7. 1000 meyve ağırlığı (g) & & & & & & - & -0.04 & 0.12 & 0.03 & -0.10 \\
\hline 8. Uçucu yağ oranı $(\%)$ & & & & & & & - & 0.18 & $-0.34^{*}$ & 0.25 \\
\hline 9. Fekon oranı (\%) & & & & & & & & - & -0.32 & $0.53^{* *}$ \\
\hline 10. Estragol oranı (\%) & & & & & & & & & - & $-037 *$ \\
\hline 11. Rakım & & & & & & & & & & - \\
\hline
\end{tabular}

*\% 5, ** \%1 düzeyinde önemli

\section{SONUÇ ve ÖNERILER}

Çalışmada doğal yayılış gösteren bitkilerin bitki boyu ve dal sayısı, şemsiye sayısı gibi bitkisel özellikler kültürü yapılan formlardan yüksek olmuş ve pek çok örnekte bitki boyu $200 \mathrm{~cm}$ üzerinde bulunmuştur. Örneklerde uçucu yağ oranları bakımından değişim fazla olmuş \% 10'un üzerinde uçucu yağ içeren örneklere rastlanmıştır. Çalışma sonucunda uçucu yağ ve estragol oranı yüksek örneklerin uçucu yağ ve estragol kaynağı amacıyla kültüre alınması ve ıslahı üzerinde yapılacak çalışmalar faydalı olacaktır.

\section{TEŞEKKÜR}

Çalışma sırasında uçucu yağ ana bileşenlerin (estragol ve fenkon) belirlenmesindeki yardımlarından dolayı Prof. Dr. Mahfuz ELMAZTAS ve Uzman Hüseyin AKŞiT'e teşekkürlerimizi sunarız. 


\section{KAYNAKLAR}

Akgün, A. 1990. Türkiye'nin Baharatları: III. Umbelliferae familyası. Gida, 15(2): 101-104

Baydar, H. 2013. Tibbi ve Aromatik Bitkiler Bilimi ve Teknolojisi (Genişletilmiş 4. Baskı). Süleyman Demirel Üniversitesi Yayın No: 51, Isparta

Bayram E., S. Kırıcı, S.Tansı, G.Yılmaz, O. Arabacı, S. Kızıl ve İ. Telci. 2010. T1bbi ve aromatik bitkiler üretiminin arttırılmas1 olanakları. Ziraat Mühendisliği VII. Teknik Kongresi Bildiri Kitabı (I): 11-15 Ocak, Ankara, s. 437-456

Baytop, T. 1994. Türkçe Bitki Adları Sözlüğü. Türk Dil Kurumu Yayınları: 578, 508 Ankara

Baytop, T. 1999. Türkiye'de Bitkilerle Tedavi (Geçmişte ve Bugün) Nobel Tip Kitapevi, İstanbul

Bernath, J., E. Nemeth, A. Kattaa and E. Hethelyi. 1996. Morphological and chemical evaluation of fennel (Foeniculum vulgare Mill.) populations of different origin. Journal of Essential Oil Research 8: 247-253.

Ceylan, A. 1987. Tibbi Bitkiler II (Uçucu Yağ İçerenler). Ege Üniversitesi Ziraat Fakültesi Yayınları No:481, Ders Kitabı: 187, İzmir

Davis, P. H. 1972. Flora of Turkey and the East Aegean Islands. Vol: 4. University Press, Edinburgh

Ehsanipour, A., J. Razmjoo and H. Zeinali. 2012. Effect of nitrogen rates on yield and quality of fennel (Foeniculum vulgare Mill.) accessions. Industrial Crops and Products 35(1): 121-125.

El-Awadi, M. E and E. A. Hassan. 2010. Physiological responses of fennel (Foeniculum vulgare Mill) plants to some growth substances. the effect of certain amino acids and a pyrimidine derivative. Journal of American Science 6(7): 120-125.

Guillen, M. D and M. J. Manzanos. 1994. A contribution to study Spanish wild grown fennel (Foeniculum vulgare Mill.) as a source of flavor compounds. Chemie, Mikrobiologie, Technologie der Lebensmittel 16: 141-145.

Mahfouz, S.A and M. A. Sharaf-Eldin. 2007. Effect of mineral vs. biofertilizer on growth, yield, and essential oil content of fennel (Foeniculum vulgare Mill.) International Agrophysics 21(4): 361-366.

Muckensturm B., D. Foechterlen, J. P. Reduron, P. Danton and M. Hildenbrand. 1997. Phytochemical and chemotaxonomic studies of Foeniculum vulgare. Biochemical Systematic and Ecology 25(4): 353-358.

Napoli, E.M., G. Curcuruto and G. Ruberto. 2010. Screening the essential oil composition of wild Sicilian fennel. Biochemical Systematic and Ecology 38(2): 213-223.

Özcan, M.M. and J.C. Chalchat. 2006. Effect of collection time on chemical composition of the essential oil of Foeniculum vulgare subsp. piperitum growing wild in Turkey. European Food Research and Technology 224: 279-281.

Özcan M.M., J.C. Chalchat, D. Arslan, A. Ateş and A. Ünver. 2006. Comparative essential oil composition and antifungal effect of bitter fennel (Foeniculum vulgare ssp. piperitum) fruit oils obtained during different vegetation. Journal of Medicinal Food 9(4): 552-561

Özkan, F. 1999 Tatlı Rezenede Bitki Sıklığının Verim ve Verim Öğeleri Üzerine Etkileri. Yüksek Lisans Tezi, Ankara Üniversitesi Fen Bilimleri Enstitüsü, Ankara

Piccaglia, R. and M. Marotti. 2001. Characterization of Some Italian Types of Wild Fennel (Foeniculum vulgare Mill.). Journal of Agricultural and Food Chemistry 49(1): 239-244.

Sencar, Ö. and S. Gökmen. 1996. Tarımsal Ekoloji. Gaziosmanpaşa Üniversitesi Ziraat Fakültesi yayınları: 8, Ders kitabı, Tokat.

Şanlı, A., T. Karadoğan and H. Baydar. 2008. Doğal olarak yetişen tatlı rezene (Foeniculum vulgare var. dulce Mill.)'nin farkl büyüme ve gelişme dönemlerinde uçucu yağ miktarı ve bileșenlerinin belirlenmesi. Süleyman Demirel Üniversitesi Ziraat Fakültesi Dergisi 3(2): 17-22.

Tanker, N., M. Kovuncu and M. Coşkun. 2004. Farmasötik Botanik. Ankara Üniversitesi Eczacılık FakültesiYayınları: 88, Ders kitabı: 458, Ankara

Telci, I., I. Demirtas and A. Sahin. 2009. Variation in plant properties and essential oil composition of sweet fennel (Foeniculum vulgare Mill.) fruits during stages of maturity. Industrial Crops and Products 30 (1): 126-130

Tunçtürk, R., M. Tunçtürk and D. Türközü. 2011. Van Ekolojik Koşullarında Değişik Azot ve Fosfor Dozlarının Rezene (Foeniculum vulgare Mill.)'de Verim ve Kalite Üzerine Etkisi. Yüzüncü Yıl Üniversitesi Tarım Bilimleri Dergisi 21(1): 19-27. 